\title{
Traffic Shaping Menggunakan Metode HTB (Hierarchical Token Bucket) pada Jaringan Nirkabel
}

\author{
Shiha Budin ${ }^{1}$, Imam Riadi \\ ${ }^{1}$ Mahasiswa Program Studi Teknik Elektro, Universitas Ahmad Dahlan, Indonesia \\ ${ }^{2}$ Dosen Program Studi Sistem Informasi, Universitas Ahmad Dahlan, Indonesia \\ Kampus 4 UAD J1. Ringroad Selatan, Tamanan, Banguntapan, Bantul, D.I. Yogyakarta 55191, Indonesia
}

\section{INFORMASI ARTIKEL}

Riwayat Artikel:

Dikirimkan 19 September 2019, Direvisi 24 Oktober 2019, Diterima 04 November 2019.

\section{Kata Kunci:}

Traffic Shaping,

Bandwidth,

Hierarchical Token Bucket, Quality of Service,

Hotspot.

\section{Penulis Korespondensi:}

Shiha Budin,

Program Studi Teknik Elektro, Universitas Ahmad Dahlan, Yogyakarta, Indonesia.

Surel/Email:

shiha1300022029@webmail.ua

d.ac.id

\begin{abstract}
ABSTRAK
Perkembangan zaman yang semakin pesat menuntut adanya layanan informasi yang lebih cepat, tepat, dan akurat menjadikan jaringan komputer sebagai kebutuhan utama. Traffic Shaping dengan Quality of Service (QoS) dapat digunakan dalam mengoptimalkan bandwidth suatu jaringan untuk menentukan jenis-jenis lalu lintas jaringan. Metode Hierarchical Token Bucket (HTB) dapat mengimplementasi pembagian trafik yang lebih akurat, dengan bandwidth yang tidak digunakan dapat dioptimalkan oleh pengguna lain. Hasil traffic shaping menggunakan metode HTB menghasilkan rata-rata indeks QoS yaitu 3,75 dan dapat dikategorikan Baik, dibandingkan sebelum menerapkan traffic shaping yaitu rata-rata 2,25 yang dikategorikan Kurang Baik. Berdasarkan hasil pengujian dapat disimpulkan bahwa kinerja jaringan hotspot dengan Traffic Shaping dan Quality of Service (QoS) dapat meningkatkan kualitas jaringan daripada sebelumnya.

The development of an increasingly rapid era requires the existence of information services that are faster, more precise, and accurate, making computer networks a primary need. Traffic Shaping with Quality of Service $(Q o S)$ can be used in optimizing the bandwidth of a network to determine the types of network traffic. The Hierarchical Token Bucket (HTB) method can implement more accurate traffic sharing, with unused bandwidth being optimized by other users. The results of traffic shaping using the HTB method produces an average QoS index of 3.75 and can be categorized Good, compared to before applying traffic shaping which is an average of 2.25 which is categorized as Poor. Based on the test results it can be concluded that the performance of hotspot networks with Traffic Shaping and Quality of Service $(Q \circ S)$ can improve network quality than before.
\end{abstract}

This work is licensed under a Creative Commons Attribution-Share Alike 4.0

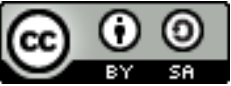

\section{Sitasi Dokumen ini:}

S. Budin and I. Riadi, "Traffic Shaping Menggunakan Metode HTB (Hierarchical Token Bucket) pada Jaringan Nirkabel," Buletin Ilmiah Sarjana Teknik Elektro, vol. 1, no. 3, pp. 144--152, 2019. DOI: $\underline{10.12928 / \text { biste.v1i3.1100 }}$ 


\section{PENDAHULUAN}

Jaringan internet merupakan gabungan dari beberapa komputer dalam suatu jaringan yang saling terhubung melalui media kabel. Perkembangan teknologi yang kini kian pesat, membuat perangkat-perangkat baru yang ada sekarang dirasa kurang efektif untuk mengaplikasikan media kabel, sehingga diciptakan teknologi jaringan yang berbasiskan wireless, atau disebut juga jaringan tanpa kabel (nirkabel) untuk dapat menjawab segala kekurangan dari media jaringan berbasis kabel [1].

Universitas Ahmad Dahlan merupakan salah satu instansi Muhammadiyah yang bergerak dibidang pendidikan di kota Yogyakarta. Universitas Ahmad Dahlan memiliki hotspot yang dapat digunakan untuk kegiatan civitas akademik serta membantu proses belajar mengajar, seperti pemanfaatan e-learning dan blog. Salah satu hotspot berada di Laboratorium Komputer dan Informatika Teknik Elektro Universitas Ahmad Dahlan (UAD). Hotspot tersebut sering digunakan untuk keperluan browsing dan lain sebagainya bagi user disekitar area hotspot.

Dengan adanya jaringan hotspot di Laboratorium Komputer dan Informatika Teknik Elektro UAD, sehingga dibutuhkan monitoring Quality of Service pada jaringan hotspot tersebut. Untuk mengoptimalkan jaringan hotspot, diperlukan manajemen bandwidth yang baik agar tidak terjadi rebutan bandwidth antar pengguna hotspot.

Penggunaan bandwidth yang lebih efisien dapat dilakukan administrator jaringan internet dengan menerapkan manajemen bandwidth dalam lalu lintas datanya menggunakan traffic shaping. Tanpa dukungan manajemen bandwidth, menyebabkan pengguna jaringan internet menggunakan bandwidth dengan tidak teratur yang menyebabkan pengguna lain tidak mendapatkan bagian bandwidth yang seharusnya didapat [2].

Metode Traffic Shaping merupakan metode yang digunakan untuk mengatur lalu lintas data ke perangkat jaringan agar alirannya sesuai dengan kecepatan yang ditentukan. Traffic shaping dapat dilakukan dengan menerapkan Hierarchical Token Bucket (HTB), kelebihan traffic shaping menggunakan metode HTB yaitu dapat membatasi traffic pada tiap level maupun klasifikasi, sehingga bandwidth yang tidak digunakan oleh pengguna yang menggunakan traffic tinggi dapat dipinjam atau digunakan oleh pengguna yang menggunakan traffic lebih rendah [3].

Penelitian terkait oleh Qalbi (2017) dengan judul: Optimalisasi Jaringan Wireless Menggunakan Quality of Service $(Q o S)$ dan Hierarchical Token Bucket (HTB). Penelitian ini menjelaskan beberapa masalah antara lain lambatnya kecepatan browsing, tetapi ada juga pengguna yang lancar dan cepat sekali melakukan browsing. Telah diimplementasikan QoS dan metode HTB dengan hasil pengukuran setelah diterapkan QoS menunjukkan rata-rata delay $=50 \mathrm{~ms}$, packet loss $=2 \%$, jitter $=6,4 \mathrm{~ms}$ dan rata-rata throughput $=128 \mathrm{~kb}$. Berdasarkan hasil pengujian dapat disimpulkan bahwa penerapan QoS dengan HTB memberikan hasil yang lebih baik dan optimal dalam manajemen bandwidth.

\section{DASAR TEORI}

\subsection{Bandwidth}

Bandwidth didefinisikan sebagai suatu data yang dapat ditransmisikan dari suatu tempat ke tempat lain dalam suatu jaringan pada waktu tertentu. Jumlah penggunaan paket data per satuan waktu juga dapat dikatakan bandwidth. Satuan bandwidth dinyatakan dengan bit per second (bps). Deretan angka yang terdiri dari 0 dan 1 atau yang dikenal dengan istilah bit atau binary digit. Banyaknya bit (angka 0 dan 1) yang dapat mengalir dari suatu tempat ke tempat lain dalam setiap detiknya melalui suatu media merupakan gambaran dari satuan ini [4].

\subsection{Traffic Shaping}

Traffic Shaping merupakan proses manajemen bandwidth untuk mengoptimalkan jaringan internet dengan menerapkan Quality of Service (QoS) sebagai penentu trafik suatu jaringan. Quality of Service (QoS) adalah teknologi yang berguna pada suatu jaringan untuk memberikan layanan adil dan merata bagi pengguna jaringan komputer. Quality of Service dapat mengontrol trafik jaringan agar tidak terjadi kemacetan (congestion) antar pengguna jaringan [4][5]. Traffic Shaping memiliki beberapa fitur, yaitu:

a. Bandwidth Priority

yaitu memprioritaskan bandwidth pada saat lalu lintas penuh, aplikasi prioritas lebih tinggi akan ditingkatkan atau diprioritaskan sehingga memperlambat prioritas yang lebih rendah.

b. Jaminan Bandwidth

yaitu pembagian batas minimal dan maksimal bandwidth ke saluran spesifik dan koneksi saluran sebenarnya. Memanfaatkan bandwidth yang berlebih pada saat tertentu, sehingga batas koneksi minimum yang didapat melebihi dari bandwidth jaminan.

c. Permintaan Bandwidth yaitu permintaan bandwidth minimal byte saat mulai melakukan koneksi sampai koneksi diakhiri. Ketika bottleneck fitur ini dapat dimanfaatkan. 
d. Penandaan Bandwidth

Yaitu indikator yang menandakan koneksi yang keluar dari batas maksimal yang diizinkan oleh suatu saluran dengan koneksi yang lain.

\subsection{Hierarchical Token Bucket (HTB)}

HTB sangat berguna untuk mengatasi bermacam-macam jenis dari sebuah trafik karena menerapkan metode kelas antrian (classful queuing). Melakukan pengelompokan-pengelompokan bertingkat dapat membuat susunan antrean dari HTB menjadi lebih terstruktur [6]. Hierarchical Token Bucket memberikan kemudahan dalam pemakaian, karena menggunakan metode peminjaman dan pembagian bandwidth yang lebih akurat. Cara ini memberikan pembatasan trafik bagi pengguna, sehingga pemakaian bandwidth dapat dioptimalkan dengan baik [3]. Hierarchical Token Bucket dapat diterapkan melalui langkah-langkah berikut:

a. Mengkonfigurasi Mangle dengan menandai setiap paket pada koneksi pengguna.

b. Mengkonfigurasi Queue dengan menginputkan CIR (Committed Information Rates), MIR (Maximum Information Rates), Parent dan prioritas dari tiap paket.

Langkah tersebut berarti permintaan bandwidth dari pengguna baik itu download ataupun upload, selanjutnya mangle akan menandai secara otomatis paket yang masuk untuk mendapatkan batasan bandwidth (baik batas atas maupun batas bawah) pada Queue. Langkah pembatasan dan penandaan ini akan tetap berjalan selama pengguna terus melakukan permintaan bandwidth [7].

\subsection{Quality of Service (QoS)}

Quality of Service didefinisikan sebagai kemampuan suatu jaringan untuk menyediakan tingkat jaminan layanan yang berbeda-beda [8]. Persentase dan nilai dari QoS menurut standarisasi jaringan versi TIPHON (Telecommunications and Internet Protocol Harmonization Over Network) [9] terlihat pada Tabel 1.

Tabel 1 Indeks parameter Quality of Service [8][10]

\begin{tabular}{ccc}
\hline Nilai & Persentase & Indeks \\
\hline 3,8 s/d 4 & $95 \%-100 \%$ & Sangat Baik \\
\hline 3 s/d 3,79 & $75 \%-94,75 \%$ & Baik \\
\hline 2 s/d 2.99 & $50 \%-74,75 \%$ & Kurang Baik \\
\hline 1 s/d 1,99 & $25 \%-49,75 \%$ & Buruk \\
\hline
\end{tabular}

Klasifikasi nilai yang terdapat pada Tabel 1 digunakan untuk menentukan seberapa baik kualitas jaringan menurut indeks Quality of Service dengan menghitung rata-rata indeks pada pengukuran Trhoughput, Packet Loss, Jitter dan Delay.

Parameter dalam Quality of Service:

a) Throughput

Merupakan variasi beban dari pengguna lain ketika menggunakan sumber yang sama. Kategori throughtput terlihat pada Tabel 2.

Tabel 2 Performansi Throughput

\begin{tabular}{ccc}
\hline Kategori & Besar Throughput & Indeks \\
\hline Sangat Baik & $76 \%-100 \%$ & 4 \\
\hline Baik & $51 \%-75 \%$ & 3 \\
\hline Sedang & $26 \%-50 \%$ & 2 \\
\hline Buruk & $<25 \%$ & 1 \\
\hline
\end{tabular}

Sumber: TIPHON

b) Packet Loss

Diartikan sebagai kegagalan transmisi paket IP dalam mencapai tujuannya. Kategori packet loss terlihat pada Tabel 3

Tabel 3 Performansi Packet Loss

\begin{tabular}{ccc}
\hline Kategori & Besar Packet Loss & Indeks \\
\hline Sangat Baik & $0 \%-2 \%$ & 4 \\
\hline Baik & $3 \%-14 \%$ & 3 \\
\hline Sedang & $15 \%-24 \%$ & 2 \\
\hline Buruk & $>25 \%$ & 1 \\
\hline
\end{tabular}

Sumber: TIPHON 
Pengukuran throughput dan packet loss menggunakan software Axence NetTools seperti pada Gambar 1. Hasil pengukuran langsung tertera pada aplikasi tersebut.

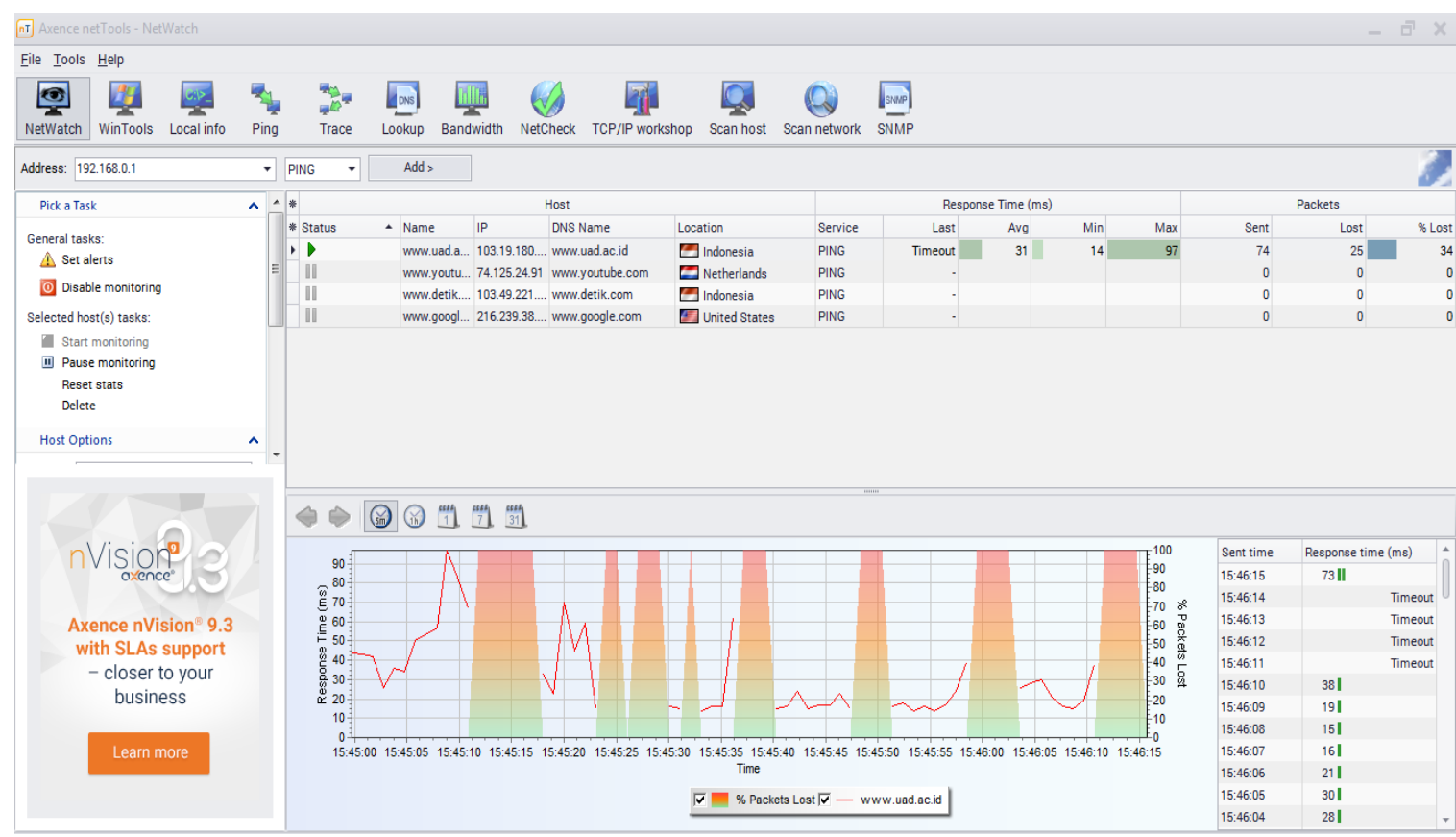

Gambar 1 Tampilan axence netTools

c) Jitter

Variasi delay antar paket yang terjadi pada jaringan berbasis IP (Internet Protocol Address). Kategori jitter terlihat pada tabel 4. Pengukuran jitter dengan menggunakan speedtest.cbn pada situs https://speedtest.cbn.id/ dengan langsung menjalankannya. Tampilan speedtest.cbn seperti Gambar 2.

Tabel 4 Performansi Jitter

\begin{tabular}{ccc}
\hline Kategori & Besar Jitter & Indeks \\
\hline Sangat Baik & $0 \mathrm{~ms}$ & 4 \\
\hline Baik & $1 \mathrm{~ms}-75 \mathrm{~ms}$ & 3 \\
\hline Sedang & $76 \mathrm{~ms}-125 \mathrm{~ms}$ & 2 \\
\hline Buruk & $126 \mathrm{~ms}-225 \mathrm{~ms}$ & 1 \\
\hline
\end{tabular}

Sumber: TIPHON

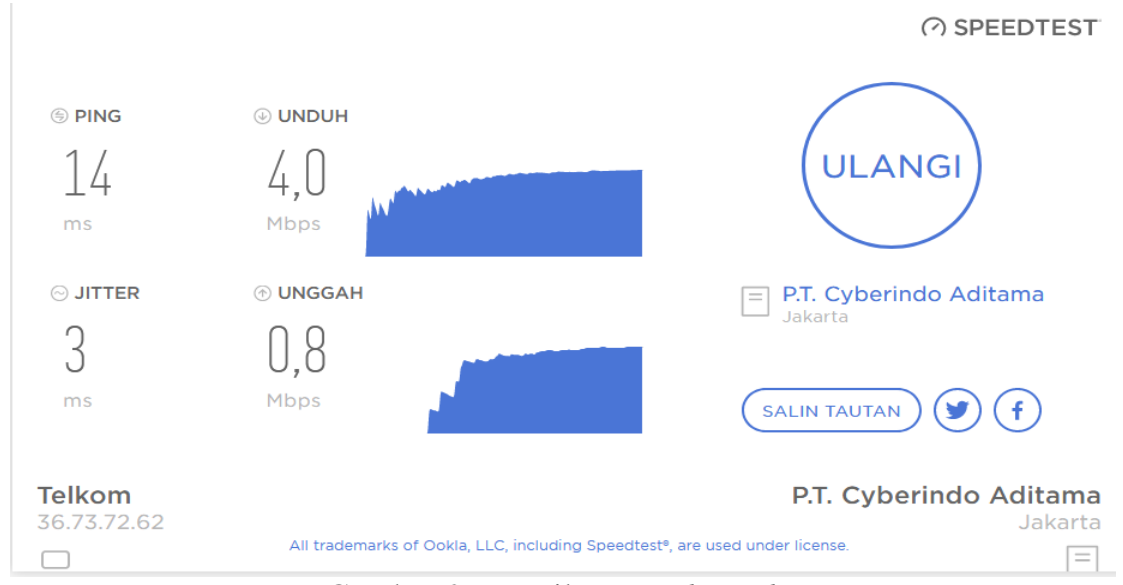

Gambar 2 Tampilan speedtest.cbn

d) Delay

Adalah proses transmisi dari suatu titik ke titik lain yang menjadi tujuan yang mengalami waktu tunda. Kategori delay terlihat pada Tabel 5.

Traffic Shaping Menggunakan Metode Hierarchical Token Bucket pada Jaringan Nirkabel (Shiha Budin) 
Tabel 5 Performansi delay

\begin{tabular}{ccc}
\hline Kategori & Besar Delay & Indeks \\
\hline Sangat Baik & $<150 \mathrm{~ms}$ & 4 \\
\hline Baik & $150 \mathrm{~ms}-300 \mathrm{~ms}$ & 3 \\
\hline Sedang & $300 \mathrm{~ms}-450 \mathrm{~ms}$ & 2 \\
\hline Buruk & $>450 \mathrm{~ms}$ & 1 \\
\hline
\end{tabular}

Sumber: TIPHON

Pengukuran jitter dengan menggunakan speedtest.net pada situs https://speedtest.net/ dengan langsung menjalankannya. Tampilan speedtest.net seperti Gambar 3.

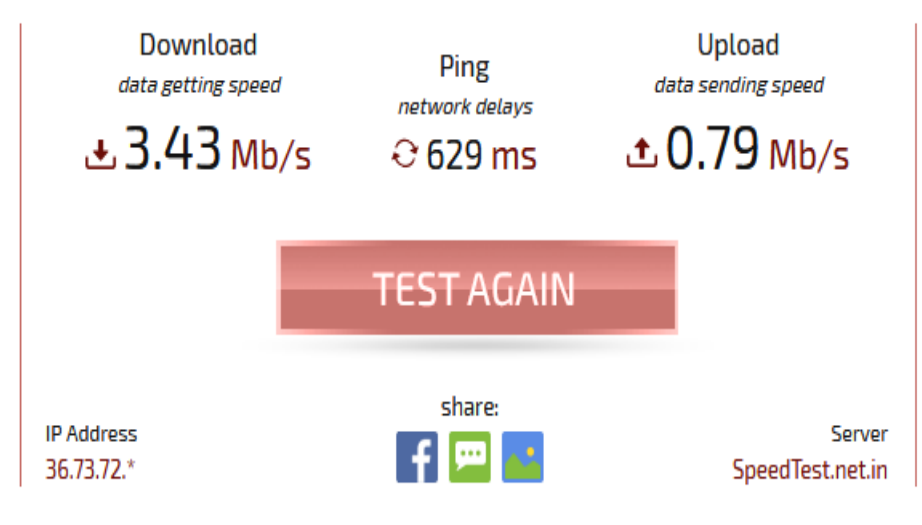

Gambar 3 Tampilan speedtest.net

Parameter Throughput, Packet Loss, Jitter dan Delay digunakan untuk mengetahui kualitas dari suatu jaringan apakah sudah memenuhi standar Quality of Service atau belum.

\section{METODE PENELITIAN}

\subsection{Proses Eksperimen}

Metode yang digunakan pada penelitian ini yaitu metode kuantitatif. Metode ini menggunakan angka sebagai data yang akan dianalisis dan digunakan untuk mengetahui apa yang ingin diteliti [10]. Tahapan penelitian kuantitatif ditunjukkan pada Gambar 4 yang berfungsi sebagai pedoman dalam pelaksanaan penelitian kuantitatif.

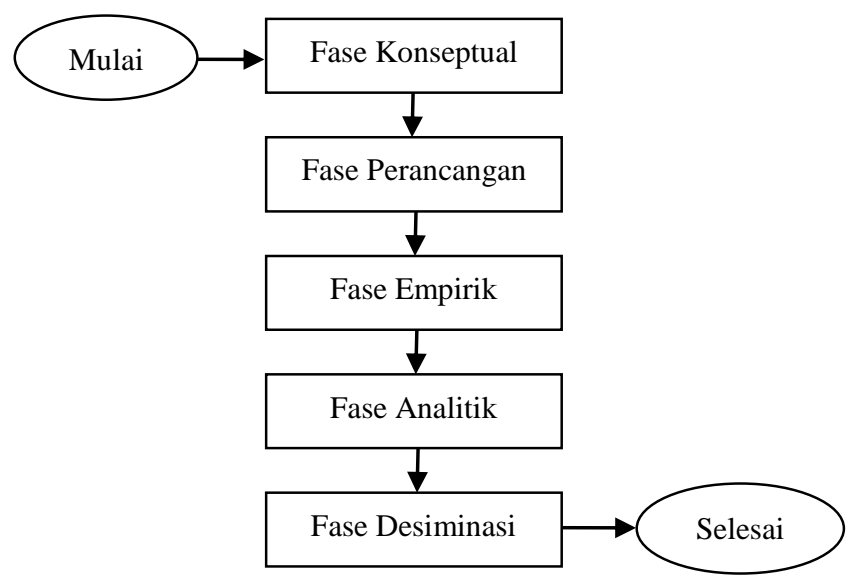

Gambar 4 Tahapan penelitian kuantitatif

1. Fase Konseptual

Merupakan awal dimulainya penelitian, seperti tahapan identifikasi masalah, rumusan masalah, dan studi literatur.

2. Fase Perancangan

Mendesain parameter dan model penelitian. Fase perancangan ini juga termasuk mendesain rancangan penelitian dari awal sampai akhir penelitian. 
3. Fase Empirik

Dilakukan pengujian pada tempat dan waktu tertentu untuk pengambilan data. Data yang telah terkumpul selanjutnya akan dianalisis.

4. Fase Analitik

Menganalisis dan mengolah data hasil penelitian. Data yang telah terkumpulkan dari pengukuran selanjutnya dianalisis dan diolah serta dilakukan evaluasi terhadap hasil-hasil penelitian sehingga didapatkan kesimpulan dari hasil penelitian yang dilakukan.

5. Fase Diseminasi

Pembuatan laporan hasil penelitian untuk memudahkan pembaca dalam memahami hasil penelitian.

\subsection{Topologi Jaringan}

Penerapan topologi untuk traffic shaping bandwidth dilakukan dengan cara mengetahui kondisi awal topologi jaringan untuk selanjutnya diimplementasikan sistem ini. Penerapan topologi jaringan dapat memberikan hasil yang maksimal jika sesuai dengan kondisi tempat penelitian. Topologi jaringan pada sistem ini terlihat pada Gambar 5.

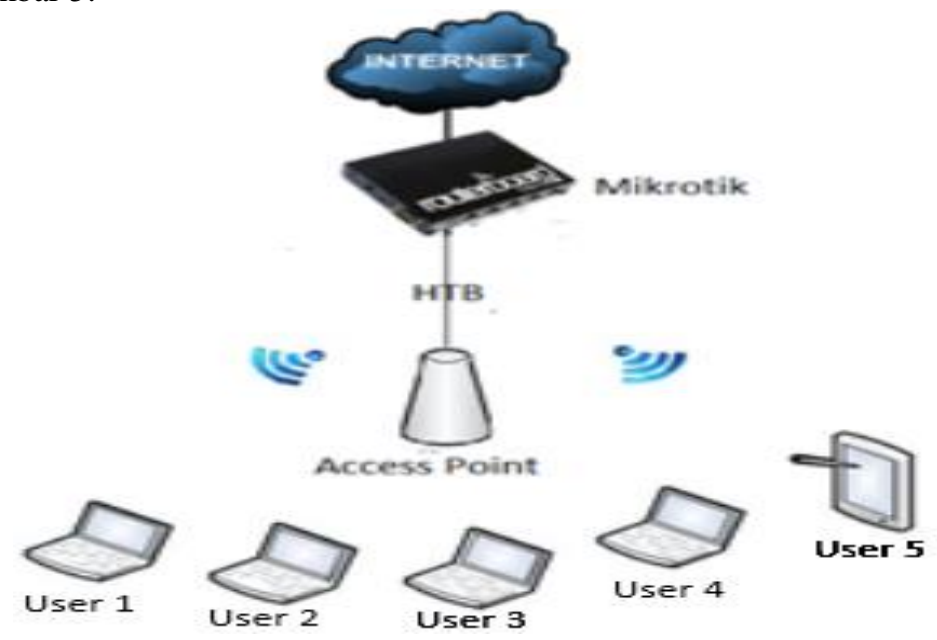

Gambar 5 Topologi jaringan

Pada Gambar 5 diketahui bahwa topologi menggunakan HTB untuk mengatur bandwidth. Jaringan hotspot diatur bandwidth-nya menggunakan router yang telah di implementasikan QoS metode HTB agar pengguna jaringan mendapatkan bandwidth yang adil.

\subsection{Diagram Blok Sistem}

Diagram blok traffic shaping bandwidth ini dengan menerapkan QoS pada jaringan nirkabel (hotspot) menggunakan implementasi metode Hierarchical Token Bucket (HTB). Rancangan sistem traffic bandwidth terlihat pada Gambar 6.

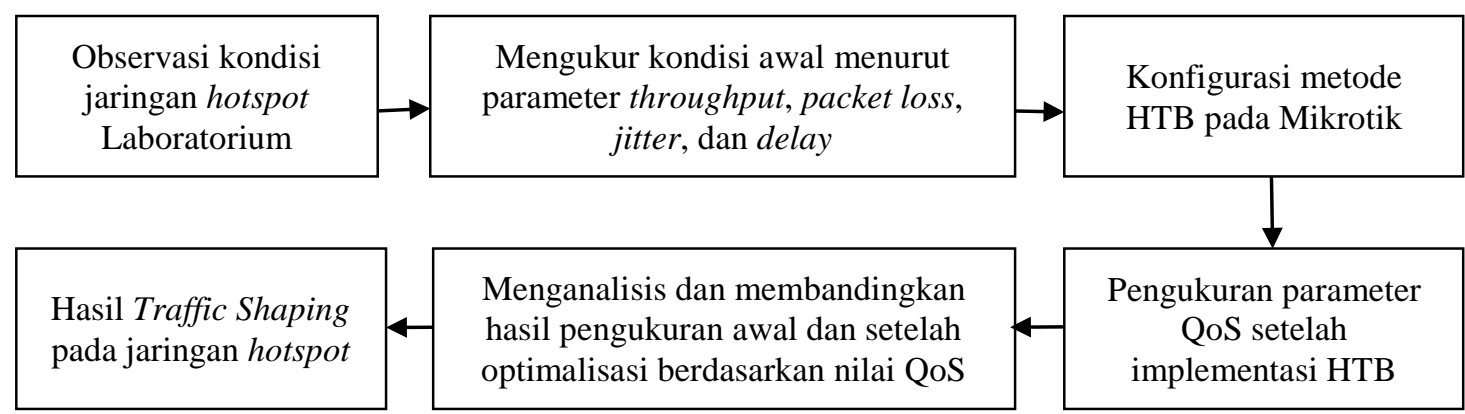

Gambar 6 Diagram Blok Desain Sistem

Tahapan-tahapan yang harus dilakukan dalam perancangan sistem analisis jaringan hotspot pada penelitian ini adalah sebagai berikut.

a. Melakukan observasi terhadap jaringan awal tempat penelitian (jaringan hotspot).

b. Melakukan pengukuran terhadap kondisi jaringan awal berdasarkan parameter QoS yaitu Throughput, Jitter, Delay, dan Packetloss. 
c. Setelah mengukur kondisi awal jaringan, selanjutnya melakukan implementasi penerapan metode pembagian bandwidth Hierarchical Token Bucket (HTB) dengan membuat konfigurasi HTB pada mikrotik.

d. Mengukur parameter QoS untuk metode pembagian bandwidth HTB.

e. Menganalisa dan membandingkan hasil penelitian sebelum dan sesudah diterapkan metode pembagian bandwidth HTB.

f. Mendapatkan hasil analisa dari pengukuran QoS jaringan hotspot.

\subsection{Flowchart Pengukuran}

Flowchart pengukuran parameter merupakan alur berjalannya sistem pengambilan data yang akan dijadikan tolak ukur data yang dibutuhkan. Parameter ini berguna untuk menentukan kualitas QoS, apakah berjalan dengan baik atau buruk. Diagram alir parameter pengukuran ini terlihat pada Gambar 7.

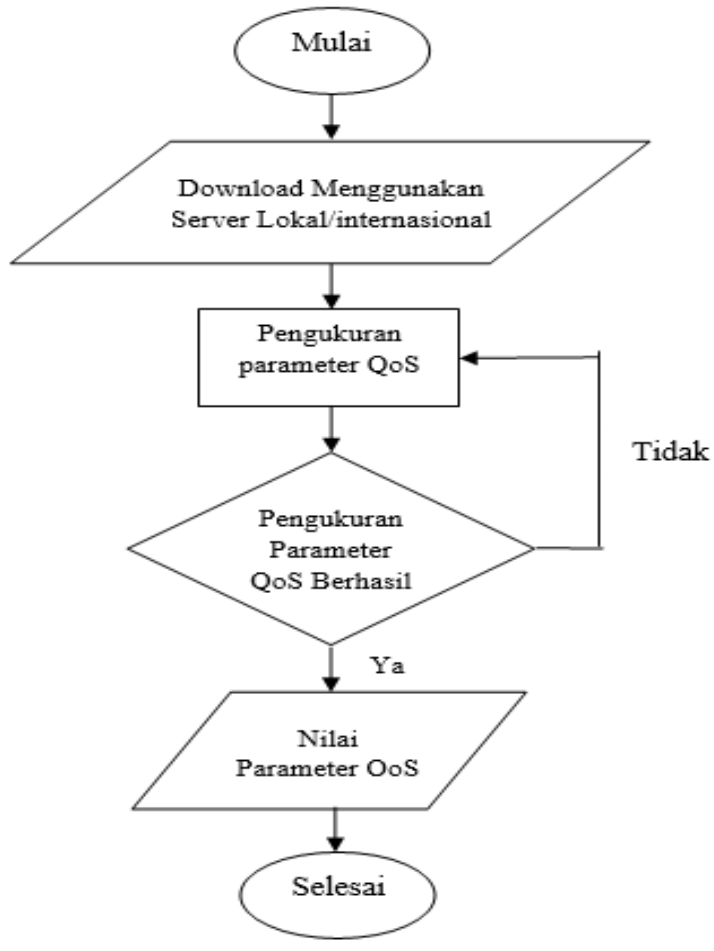

Gambar 7 Flowchart pengukuran

Pada gambar 7 pengukuran dilakukan dengan melakukan upload atau download file. Setelah melakukan upload atau download, sistem akan menghitung kualitas jaringan menggunakan parameter QoS. Apabila berhasil akan didapatkan nilai parameter, jika pengukuran gagal maka dilakukan pengukuran kembali.

\section{HASIL DAN PEMBAHASAN}

\subsection{Implementasi}

Pengukuran kualitas kinerja jaringan dengan menerapkan metode Hierarchical Token Bucket (HTB) menurut parameter QoS yaitu Throughput, Packet Loss,Jitter, dan Delay. Dilakukan pengukuran sebelum implementasi metode Hierarchical Token Bucket dan setelah diimplementasikan untuk mengetahui perbedaan sebelum dan sesudah implementasi.

\subsection{Pengukuran Awal}

Hasil pengukuran kualitas Quality of Service pada kondisi awal jaringan terlihat pada Tabel 6. Pada Tabel 6 hasil throughput pada pengukuran ke-1 dan ke-3 merupakan hasil pengukuran terendah dan masuk kategori buruk, sedangkan pengukuran ke-2, 3 dan 5 mendapatkan hasil dalam kategori sangat baik. Hasil pengukuran packet loss dalam keadaan baik pada pengukuran ke-2 dan ke-5, pengukuran ke-3 kondisi sedang, dan pengukuran ke-1 dan ke-3 dalam kondisi buruk. Hasil jitter pada pengukuran ke-1,3 dan 6 kategori baik, pengukuran ke-2 kategori sedang, dan pengukuran ke-4 kategori buruk. Hasil delay pada pengukuran ke-1 kategori sangat baik, pengukuran ke-2,3 dan 4 dalam kategori baik, dan hasil pengukuran ke-5 dalam kategori sedang. 
Tabel 6 Pengukuran kondisi awal

\begin{tabular}{ccccc}
\hline Pengukuran ke- & Througput $(\boldsymbol{\%})$ & Packet Loss $(\boldsymbol{\%})$ & Jitter (ms) & Delay (ms) \\
\hline 1 & 23 & 70 & 30 & 100 \\
\hline 2 & 90 & 7 & 65 & 200 \\
\hline 3 & 93 & 17 & 145 & 206 \\
\hline 4 & 32 & 52 & 36 & 369 \\
\hline 5 & 85 & 7 & 80 & 216,4 \\
\hline Rata-rata & 64,6 & 30,6 & & 65 \\
\hline
\end{tabular}

Nilai rata-rata pengukuran Throughput sebesar 64,6\% (Baik), Packet Loss sebesar 30,6\% (Buruk), Jitter sebesar 80 ms (Sedang) dan Delay sebesar 216,4 ms (Baik). Menurut hasil rata-rata tersebut, kinerja jaringan pada kondisi awal masih kurang maksimal dan terjadi transmisi data yang tidak lancar dikarenakan nilai packet loss dan jitter dalam kategori buruk dan sedang.

\subsection{Implementasi Hierarchical Token Bucket (HTB)}

Hasil pengukuran kualitas Quality of Service menggunakan metode HTB terlihat pada Tabel 7. Berdasarkan Tabel 7 hasil pengukuran throughput, packet lossdan jitter pada pengukuran ke-1 sampai pengukuran ke-5 masuk dalam kategori sangat baik. Hasil pengukuran delay pada pengukuran ke-1 dalam kategori baik dan pada pengukuran ke-2 sampai pengukuran ke-5 kategori sangat baik.

Tabel 7 Pengukuran metode HTB

\begin{tabular}{ccccc}
\hline Pengukuran ke- & Througput $(\boldsymbol{\%})$ & Packet Loss $\mathbf{( \% )}$ & Jitter $(\mathbf{m s})$ & Delay $(\mathbf{m s})$ \\
\hline 1 & 100 & 0 & 10 & 190 \\
\hline 2 & 100 & 0 & 4 & 105 \\
\hline 3 & 100 & 0 & 3 & 92 \\
\hline 4 & 100 & 0 & 3 & 92 \\
\hline 5 & 100 & 0 & 6 & 92 \\
\hline Rata-rata & 100 & 0 & 5,2 & 114,2 \\
\hline
\end{tabular}

Hasil rata-rata trhoughput sebesar 100\% (Sangat Baik), Packet Loss sebesar 0\% (Sangat Baik), Jitter sebesar 5,2 ms (Baik) dan Delay 114,2 ms (Sangat Baik). Hasil yang didapat setelah mengimplementasikan metode HTB mengalami perubahan yang lebih baik daripada pengukuran kondisi awal dan menunjukkan transmisi data berjalan lebih lancar.

\subsection{Analisis Hasil Pengukuran}

Proses pengukuran yang telah dilakukan, mulai dari pengukuran awal sampai implementasi metode pembagian bandwidth, selanjutnya dilakukan analisis hasil pengukuran dengan cara perbandingan terhadap nilai standar Quality of Service itu sendiri dan menjadi bahan acuan pada penelitian ini.

Berdasarkan hasil pengukuran Quality of Service dapat disimpulkan indeks kualitas jaringan berdasarkan nilai rata-rata seperti pada Tabel 8.

Tabel 8 Indeks hasil pengukuran awal dan implementasi QoS

\begin{tabular}{|c|c|c|c|c|}
\hline Metode & Parameter QoS & Hasil Pengukuran & Standar TIPHON & Indeks Nilai \\
\hline \multirow{5}{*}{ Awal } & Throughput & $64,6 \%$ & Baik & 3 \\
\hline & Packet Loss & $30,6 \%$ & Buruk & 1 \\
\hline & Jitter & $80 \mathrm{~ms}$ & Sedang & 2 \\
\hline & Delay & $216,4 \mathrm{~ms}$ & Baik & 3 \\
\hline & & Hasil Rata-rata & & 2,25 \\
\hline \multirow{5}{*}{ HTB } & Throughput & $100 \%$ & Sangat Baik & 4 \\
\hline & Packet Loss & $0 \%$ & Sangat Baik & 4 \\
\hline & Jitter & $5,2 \mathrm{~ms}$ & Baik & 3 \\
\hline & Delay & $114,2 \mathrm{~ms}$ & Sangat Baik & 4 \\
\hline & & Hasil Rata-rata & & 3,75 \\
\hline
\end{tabular}

Berdasarkan Tabel 8 nilai rata-rata indeks pada pengukuran awal yaitu 2,25 dan menurut indeks parameter Quality of Service (QoS), hasil tersebut dapat dikategorikan Kurang Baik, sedangkan hasil rata-rata indeks QoS menggunakan metode HTB yaitu 3,75, dan menurut indeks parameter Quality of Service (QoS) hasil tersebut dapat dikategorikan Baik. Hasil rata-rata indeks QoS menunjukkan bahwa ada peningkatan kualitas jaringan sebelum dan sesudah implementasi metode Hierarchical Token Bucket. 


\section{KESIMPULAN}

Metode Hierarchical Token Bucket (HTB) dapat digunakan untuk melakukan pembagian bandwidth. Hasil pengukuran awal sebelum menerapkan QoS yaitu: throughput 64,6\% (Baik), packet loss 30,6\% (Buruk), jitter $80 \mathrm{~ms}$ (Sedang), delay 216,4 ms (Baik). Setelah melakukan implementasi pembagian bandwidth menggunakan metode HTB didapatkan hasil yaitu throughput 100\% (Sangat Baik), packet loss 0\% (Sangat Baik), jitter 5,2 ms (Baik), delay 114,2 ms (Sangat Baik). Berdasarkan hasil pengujian dapat disimpulkan bahwa kinerja jaringan hotspot dapat digunakan dengan baik dan dapat meningkatkan kinerja hotspot dari kondisi semula berupa pembagian bandwidth yang lebih adil.

\section{UCAPAN TERIMA KASIH}

Sampaikan ucapan terima kasih kepada editor dan reviewer atas segala saran, masukan dan telah membantu dalam proses penerbitan naskah. Ucapan terima kasih juga ditunjukkan kepada pihak-pihak yang telah mendukung penelitian dan memberikan bantuan moral dan material.

\section{REFERENSI}

[1] B. Sugiantoro and Y. B. Mahardhika, "Analisis Quality Of Service Jaringan Wireless Sukanet Wifi Di Fakultas Sains Dan Teknologi Uin Sunan Kalijaga,” J. Tek. Inform., vol. 10, no. 2, pp. 191-201, 2018. DOI: 10.15408/jti.v10i2.7027

[2] P. Silitonga and I. S. Morina, "Analisis QoS (Quality of Service) Jaringan Kampus dengan Menggunakan Microtic Routerboard," J. TIMES, vol. 5, no. 69, pp. 12-17, 2014. Google Scholar

[3] A. I. Wijaya and L. B. Handoko, "Manajemen Bandwidth Dengan Metode Htb ( Hierarchical Token Bucket ) Pada Sekolah Menengah Pertama Negeri 5 Semarang," J. Tek. Inform. Udinus, vol. 1, no. 1, pp. 5-7, 2014. DOI: $\underline{10.24076 / \text { citec.2018v5i3.237 }}$

[4] I. Riadi, "Optimasi Bandwidth Menggunakan Traffic Shaping," J. Inform., vol. 4, no. 1, pp. 374-382, 2010. Google $\underline{\text { Scholar }}$

[5] M. Syaifulah, "Metode Traffic Shaping Pada Layer 7 Protocol Untuk Mengoptimalkan Kinerja Jaringan Komputer Menggunakan Mikrotik (Studi Kasus Di SMK Negeri 1 Bukit Batu),” J. Ilmu Komput. dan Bisnis, vol. 8, no. 1, pp. 1890-1934, 2017. Google Scholar

[6] Lisnawita, "Manajemen Bandwidth Menggunakan Metode Hierarchical Token Bucket," J. Teknol. Inormasi Komun. Digit. Zo., vol. 7, no. 1, pp. 18-25, 2016. DOI: 10.31849/digitalzone.v7i1.520

[7] Y. Arifin, "Implementasi Quality Of Service Dengan Metode HTB (Hierarchical Token Bucket) PADA PT. KOMUNIKA LIMA DUABELAS," J. Elektron. Ilmu Komput., vol. 1, no. May 2014, p. 32, 2012. Google Scholar

[8] R. Wulandari, "Analisis Qos (Quality Of Service) Pada Jaringan Internet (Studi Kasus : Upt Loka Uji Teknik Penambangan Jampang Kulon - Lipi),” J. Tek. Inform. dan Sist. Inf., vol. 2, no. 2, pp. 162-172, 2016. DOI: 10.28932/jutisi.v2i2.454

[9] Telecommunications and Internet Protocol Harmonization Over Networks (TIPHON) General aspects of Quality of Service (QoS), “ TR 101 329,” ETSI Technical Report, 1999. Online

[10] I. Iskandar and A. Hidayat, "Analisa Quality of Service (QoS) Jaringan Internet Kampus (Studi Kasus: UIN Suska Riau)," J. CoreIT, vol. 1, no. 2, pp. 67-76, 2015. DOI: $\underline{10.24014 / \text { coreit.v1i2.1233 }}$

\section{BIOGRAFI PENULIS}

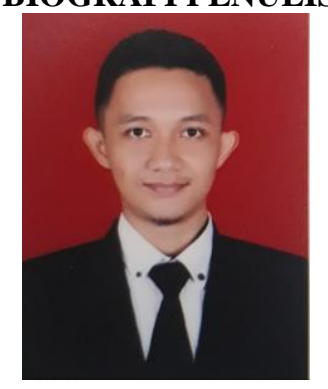

Shiha Budin

Lahir di Riau. Menyelesaikan pendidikan S1 Program Studi Teknik Elektro, Fakultas Teknologi Industri, Universitas Ahmad Dahlan Yogyakarta.

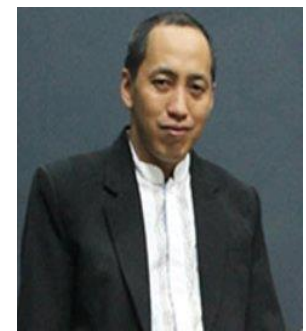

\section{Imam Riadi}

Lahir di Kudus. Menyelesaikan pendidikan S1 Pendidikan Teknik Komputer/Teknik Elektro di Universitas Negeri Yogyakarta, S2 dan S3 Ilmu Komputer di Universitas Gajah Mada Yogyakarta dengan judul Disertasi "Framework Untuk Forensik Internet Menggunakan kmeans Clustering dan Horizontal Partitioning”. Saat ini beliau adalah dosen aktif di Program Studi Sistem Informasi Universitas Ahmad Dahlan Yogyakarta. 